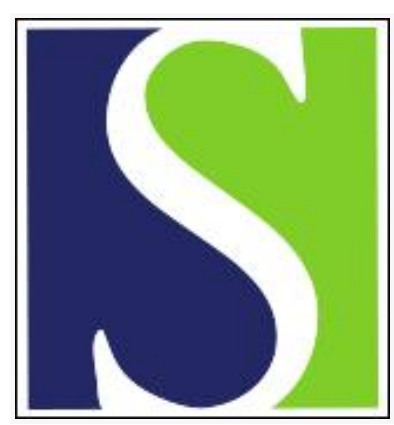

Scand J Work Environ Health 1976;2(3):190-198

https://doi.org/10.5271/sjweh.2806

Issue date: Sep 1976

Determination of exposure to electric fields in extra high voltage substations.

by Lövstrand KG

Key terms: capacitive current; discharge; electric field measurement; electric fields; exposure; extra high voltage; extra high voltage substation; high voltage; high voltage substation; personnel; substation; transmission line

This article in PubMed: www.ncbi.nlm.nih.gov/pubmed/973131

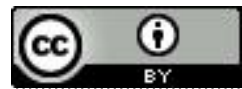




\title{
Determination of exposure to electric fields in extra high voltage substations
}

\author{
by K. G. LÖVSTRAND, Ph.D.1
}

\begin{abstract}
LÖVSTRAND, K. G. Determination of exposure to electric fields in extra high voltage substations. Scand. $j$. work environ. \& health 3 (1976) 190-198. Electrophysical effects related to extra high voltage are surveyed for the determination of the exposure of personnel to electric fields in substations. It is concluded that the electric field strengths and the electrical discharges to the personnel are the important electrophysical factors. Instruments for measuring the field strength at grounded surfaces and at nonzero potentials were constructed. Results are presented of measurements with these instruments in substations. A dummy was used for the measurement of the distribution of capacitive currents to a man. The dummy can also be used for measuring the effectiveness of special shielding clothes.
\end{abstract}

Key words: extra high voltage, transmission line, substation, exposure, personnel, electric field measurement, discharge, capacitive current.

Some investigations have indicated that the exposure of personnel, working in extra high voltage $(\mathrm{EHV})^{2}$ substations, to high electric field strengths of power frequency $(50 \mathrm{~Hz}$ or $60 \mathrm{~Hz})$ may cause physiological changes $(2,7,10)$. The results led to a Soviet limitation of the occupational exposure to high field strengths in EHV switchyards and near EHV transmission lines.

Several similar studies have been made, however, in which no significant physiological effects were observed (17). Some laboratory experiments on mice have shown reversible physiological effects of long-time exposure to high electric field strengths (13), whereas others have not shown any significant effects. High volt-

1 The Research Institute of Electricity, Uppsala, Sweden.

$2 \mathrm{EHV}=130 \mathrm{kV}-800 \mathrm{kV}$.

Reprint requests to: Dr. K. G. Lövstrand, The Research Institute of Electricity, Husbyborg, S-755 90 Uppsala, Sweden. age constructions are surrounded by electric fields, the strength and extension of which are dependent on the operating voltage and the dimensions of the construction. Higher voltages have resulted in more pronounced effects $(7,8,10)$.

The maximum voltage of main EHV transmission lines in Sweden is at present $400 \mathrm{kV}$, but a $800 \mathrm{kV}$ transmission line is under construction and should be in operation within a few years.

In 1974 the Swedish State Power Board, in cooperation with the National Board of Occupational Safety and Health and the Research Institute of Electricity, started physiological, psychological, and physical investigations of the effects of electric fields on personnel in Swedish EHV substations. The investigations are expected to show if special precautions, such as shielding clothes or permanent or mobile electric shields, are necessary for the protection of the personnel working in the vicinity of the $800 \mathrm{kV}$ constructions. 
The present report presents the electrophysical phenomena and effects related to the EHV and the instruments which were developed for the determination of occupational exposure to electric fields in substations.

\section{MATERIAL AND METHODS}

\section{Electrophysical effects caused by EHV}

For the physical part of the investigation a survey was made of the electrophysical effects caused by EHV. The aim was to find relevant physical parameters which might be related to the medical observations made during the investigation.

With the support of previous investigations some effects could be excluded from the study.

Corona discharges occur at surfaces with a high field strength, such as wire conductors and disconnector busbars. The number of corona discharges increases during certain weather conditions, such as drizzle or misty weather.

Corona discharges produce a large number of air ions and also ozone. The physiological effects of an increased air ion density are not well known, but some investigations have shown negative health effects at high air ion concentrations $(9,11)$.

The increase in the air ion density was not very high a few meters away from outdoor AC EHV constructions. Air ions were thus excluded from the investigation.

An investigation by Fern and Brabets (6) showed that no significant increase in ozone concentration is to be expected near outdoor EHV constructions such as transmission lines or substations.

Electric conductors, e.g., in transmission lines with current flowing through them, are surrounded by magnetic fields. The flux density $B$ depends on the distance $r$ to a conductor and on the current I flowing through it. B(r) can easily be calculated for a single straight conductor of infinite length.

$$
\mathrm{B}(\mathrm{r})=\mu_{0} \mathrm{I} / 2 \pi \mathrm{r}
$$

where $\mu_{0}=4 \pi \cdot 10^{-7} \quad(\mathrm{Vs} / \mathrm{Am})$.

The maximum currents in EHV transmission lines are on the order of 1,000 A, and the safety distance to EHV conductors is about $3 \mathrm{~m}$. If $\mathrm{r}=3 \mathrm{~m}$ and $\mathrm{I}=1,000 \mathrm{~A}$ equation 1 gives $\mathrm{B}=6 \cdot 10^{-5} \mathrm{~T}$.

The magnetic flux density limit (VLF) recommended for "long-time" occupational exposure is $2 \cdot 10^{-2} \mathrm{~T}$ at the Stanford Linear Accelerator Center in the U.S.A. and $3 \cdot 10^{-2} \mathrm{~T}$ in the U.S.S.R. (12). The flux density near a current-carrying conductor is thus more than two orders of magnitude below the recommended maximum exposure values. The health effect, if any, should thus be negligible during ordinary work at the constructions. Certain "hotline" operations bring the personnel very close to the current-carrying conductors. Such operations require special attention.

The electromagnetic radio noise emission from the corona discharges was not considered to be intense enough to have any influence on the medical parameters studied (16). Exposure to high electric field strengths in work areas at EHV constructions is the factor that has been considered the most important for suspected negative health effects (13). Capacitive coupling of the AC voltage to a man standing in the electric field gives rise to a capacitive current which flows through his conducting body. This current can be $0.1-1 \mathrm{~mA}$.

If an insulated person standing in the electric field touches a grounded object, he may feel a discharge at the point of contact. In such very short $(\tau<1 \mu \mathrm{s})$ discharges the peak current, which depends on the field strength acting on the person and the impedance of the contact (the series impedance of the discharge channel, the skin, and the body), can be about $10 \mathrm{~A}$ (8). Such occurrences are well known to personnel working in EHV substations. Accidents have also occurred because of the uncontrollable jerks which follow strong discharges. In a work made by Filippov and Morozov (8) the mean lower limit of the field strength for painful discharges was found to be $5.2 \mathrm{kV} / \mathrm{m}$. The intensity of a discharge depends on the mean electric field strength acting on the person, his capacitance to earth, and the phase of the alternating electric 
field at the moment of contact. The last factor will cause the discharge energy to vary in a series of contacts, even if the capacitance and the field strength are constant. The statistical distribution of the discharge energy can be calculated from the capacitance to earth and the field strength. A slow speed of touching the grounded surface can cause a series of discharges to occur for each contact, one for each half-period of the alternating electric field (8).

It was concluded from this review of the physical effects related to EHV that the electric field strength, the capacitive currents, and the electric discharges to persons were the parameters which most justified being studied.

\section{Electric field theory}

It is comparatively simple to calculate the electric field in some electrode geometries. The electric field $\mathrm{E}$ between a straight conductor above the ground can be obtained from three equations. The first yields the charge density $q$ in the conduc-

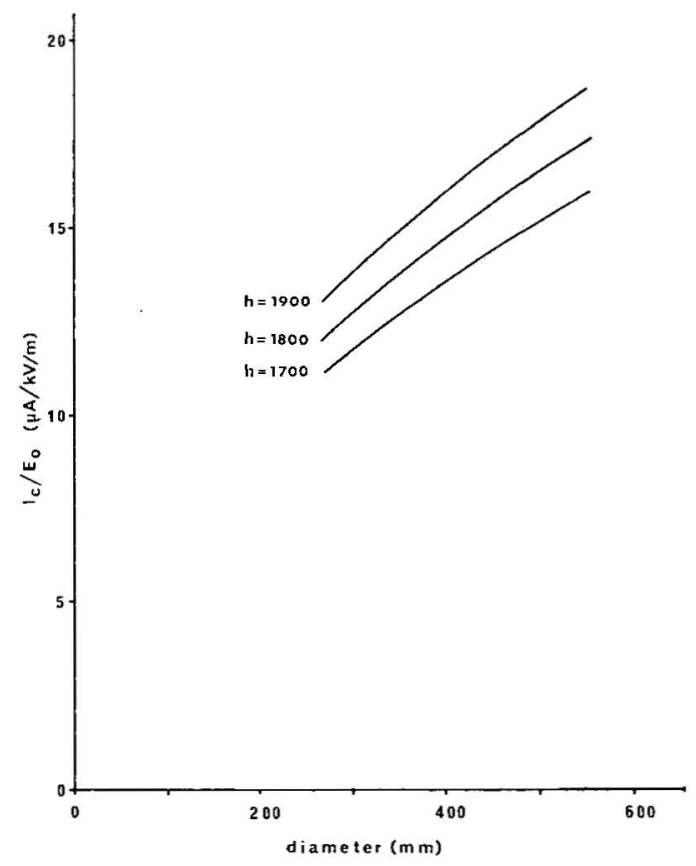

Fig. 1. Capacitive current $I_{c}$ to a semispheroid exposed to a $50-\mathrm{Hz}$ electric field. $\left(\mathrm{E}_{0}=1 \mathrm{kV} / \mathrm{m}, \mathrm{h}=\right.$ the height of the spheroid in millimeters). tor as a function of the voltage $\mathrm{V}$ and the capacitance to the ground $\mathrm{C}$ :

$\mathrm{q}=\mathrm{V} / \mathrm{C}$.

The second yields the capacitance $\mathrm{C}$ as a function of the height $h$ and radius $r$ of the conductor:

$\mathrm{C}=1 / 2 \pi \varepsilon_{0} \ln (2 \mathrm{~h} / \mathrm{r})$,

and the third yields the electric field strength $\mathrm{E}$ as a function of $\mathrm{q}, \mathrm{h}$, and the horizontal distance $x$ to the field strength point:

$\mathrm{E}=2 \mathrm{qh} / 4 \pi \varepsilon_{0}\left(\mathrm{~h}^{2}+\mathrm{x}^{2}\right)$,

where $\varepsilon_{0}=10^{-9} / 36 \pi . \quad(\mathrm{As} / \mathrm{Vm})$

One single EHV transmission line consists however of three phase conductors and at least one ground wire. The alternating voltage of the phase conductors shifts $120^{\circ}$ in phase angle for each "phase." Accordingly the resulting electric field at any space point is a sum of three field vectors with a $120^{\circ}$ phase difference. The electric field vectors from the conductors are disturbed in magnitude and direction by the presence of the other conductors, the ground wire, and the ground. The field is further disturbed near the towers of the line. Calculations of the electric field strength at the ground level under transmission lines have been made by several authors $(1,15)$. The calculations are complicated when several conductors cross each other and several objects on the ground disturb the field.

Approximate calculations can be made of the electric field strength at the surface of conducting objects on the ground near EHV constructions. Deno $(4,5)$ has reported methods for several such approximations. He has also shown how the capacitive currents can be calculated with approximate geometries. The currents can be very dangerous or even fatal. Accidents have occurred when persons have touched large insulated conducting objects or insulated construction parts and have thus formed a short circuit of a sometimes fatal capacitive current to the ground.

For field and capacitive current calculations a person standing on the ground can be approximated with a semispheroid, a spheroid, or a cylinder with a hemisphere at the top end. The influence of the 


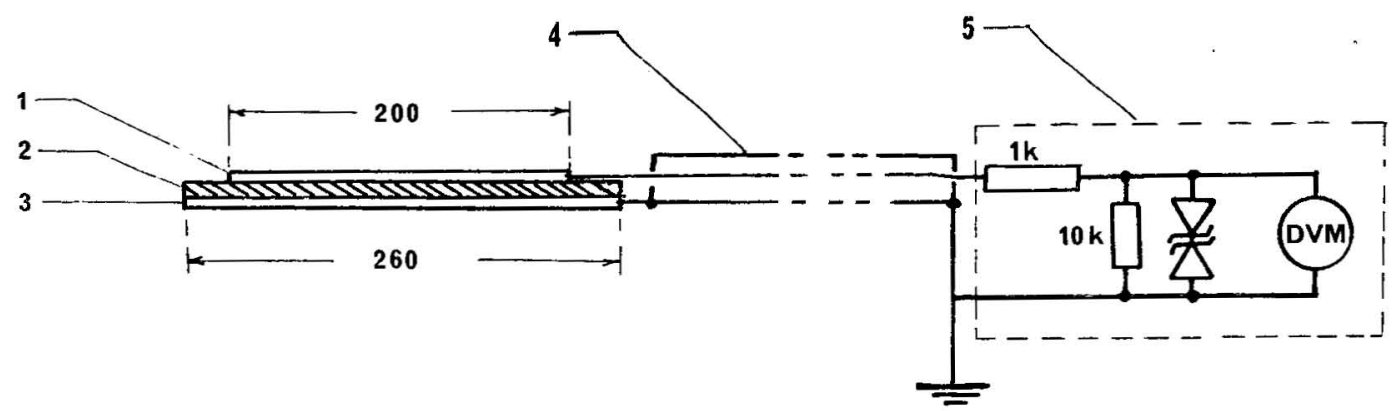

Fig. 2. Instrument for the measurement of the $\mathrm{AC}$ electric field strength at a grounded surface. ( 1 = capacitive electrode, $2=$ insulation, $3=$ grounded electrode, $4=$ coaxial cable, and $5=$ shielding instrument box)

thickness and height of a person can thus be calculated (3). Fig. 1 shows the influence of height and thickness on the capacitive current to a man standing in a $50-\mathrm{Hz}$ homogeneous electric field when the man is approximated with a semispheroid.

Instrument for measuring electric field strength at a grounded conducting surface

Gauss' law yields the induced charge density $\sigma$ at a conducting surface due to the external electric field strength $\mathrm{E}$

$\sigma=\mathrm{E} \varepsilon \varepsilon_{0}$

where $\varepsilon=1$ for a field in air. If the electric field is alternating with a frequency $\omega$, it can be represented by a displacement current flowing into the surface with a current density $j$, where

$\mathrm{j}=\omega \mathrm{E} \varepsilon \varepsilon_{0}$.

This gives a method for measuring field strength at conducting surfaces.

A conducting flat probe can be placed on the grounded surface and connected to the earth via an $\mathrm{AC}$ ammeter. The field strength can be calculated from the current flowing into the plate if the area of the plate $S$ and the frequency $\omega$ of the field are known:

$\int \mathrm{E} \cdot \mathrm{dS}=\mathrm{I} / \omega \varepsilon_{0}$

$\mathrm{S}$

where $\varepsilon=1$ for air or if $\mathrm{E}$ is homogeneous over $\mathbf{S}$ :

$\mathbf{E}=\mathrm{I} / \varepsilon \varepsilon_{0} \omega \mathrm{S}$.
For accurate measurements the connection to the ammeter should be shielded and the impedance to earth of the connecting cable should be much greater than the inner impediance of the ammeter. The time constant $\mathrm{RC}$ of the ammeter resistance $R$ and the sum of cable capacitance and plate capacitance to earth $\mathrm{C}$ should be

$\mathrm{RC}<<1 / \omega$.

For a sandwich probe with a grounded electrode below the insulated capacitive electrode, the capacitance is:

$\mathrm{C}_{\mathrm{p}}=\mathrm{S} / \mathrm{d}\left(\varepsilon_{\mathrm{i}} \varepsilon_{0}\right)$,

where $S$ is the area of the capacitive electrode, $\mathbf{d}$ is the thickness of the insulation, and $\varepsilon_{\mathrm{i}}$ is the relative dielectric constant of the insulator material.

A field strength measuring system was constructed according to this principle. The field strength probe was a round plate of $3 \cdot 10^{-2} \mathrm{~m}^{2}$. It was connected to a data precision digital voltmeter via a $1-\mathrm{m}$ coaxial cable. A $10^{4} \Omega$ resistor was connected in parallel with the voltmeter. The capacitive current was thus measured with the digital voltmeter (fig. 2). The voltmeter was protected with a combined zener diode - gas discharge tube transient protection. The probe was calibrated for $50 \mathrm{~Hz}$ in a known electric field between parallel plates. Similar instruments have been used by Schneider et al. (15) and Miller (14).

The use of the capacitive probe is limited to grounded surfaces because the potential of the probe is that of the ground. 

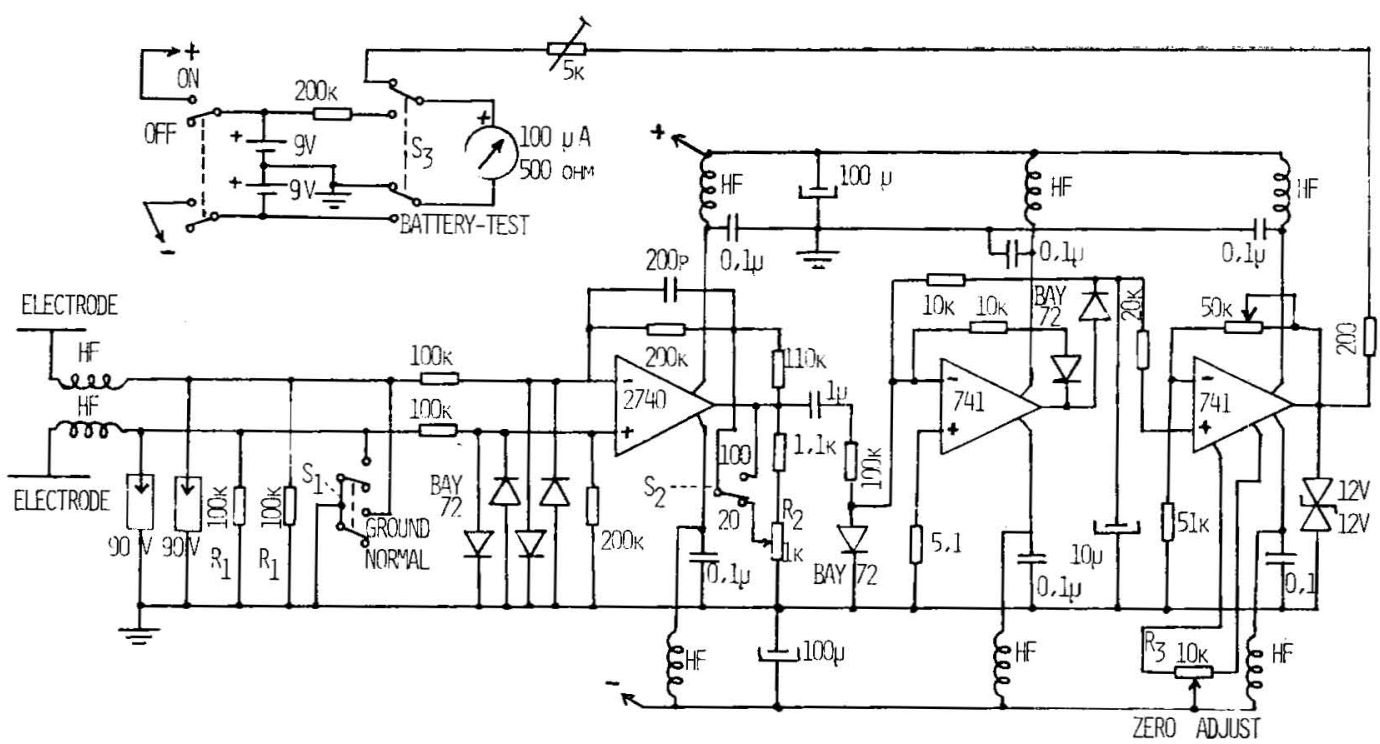

Fig. 3. Instrument for the measurement of the AC electric field strength at points with nonzero potential - circuitry.

If the probe is put up at space point with a nonzero potential, a strong disturbance of the electric field will be introduced at the measuring point, and too high values are measured (14).

Electric field strength at nonzero potential points

Two capacitive probes arranged as a symmetric dipole can be used for measurement of the field strength at a point with a nonzero potential $(8,15)$. The current flowing between the plates is then proportional to the time derivative of the field strength component in the dipole direction. Consequently this instrument is direction sensitive. The two dipole halves can be arranged as the two halves of a sphere or a spheroid (14). The dipole introduces a disturbance of the field by short-circuiting part of it. This disturbance and the sensitivity can easily be calculated for spheric or spheroidal dipoles, and they can be measured by calibration for other dipole geometries.

According to this principle a symmetric dipole instrument was constructed with flat rectangular electrodes. The electrodes were placed at opposite sides of a shielding metal case, $90 \times 100 \times 200 \mathrm{~mm}$, which contained the electronics. The electronic circuit of the instrument is shown in fig. 3 .

The circuit consists of a transient protection device, the current shunt resistances $R_{1}$, a two-stage voltage amplifier, and a rectifier. Two sensitivities, $20 \mathrm{kV} / \mathrm{m}$ or $100 \mathrm{kV} / \mathrm{m}$ full-scale, can be selected by the switch $\mathrm{S}_{2}$. The sensitivity of the instrument is adjusted with the potentiometer $R_{2}$. The amplifier zero output is adjusted with potentiometer $R_{3}$ with the input short-circuited by switch $S_{1}$. The battery condition can be tested by the operation of switch $S_{3}$. The field strength is displayed on an instrument at the front panel of the case (fig. 4).

The instrument can be placed at the top of a thin insulating rod with a known height. Useful measurements can also be made with the instrument attached to a $0.5-\mathrm{m}$ long insulating handle, which is held by the hand with the arm outstretched.

The instrument was calibrated in a known homogeneous electric field between two large parallel metal plates.

Test measurements have also been made with the instrument held in the hand below a long single horizontal EHV conductor. The accuracy of such measurements at a height of $1-2 \mathrm{~m}$ proved to be better than $5 \%$. 
It is essential that the instrument be corona-free during measurements. In an electric field $E_{y}(\mathrm{kV} / \mathrm{m})$ the appoximate voltage disturbance $U_{d}$ of the space potential at one end of the dipole will be $\mathrm{U}_{\mathrm{d}} \approx \mathrm{E}_{\mathrm{y}} \cdot \mathrm{d} / 2(\mathrm{kV})$,

where $d$ is the length of the dipole. For $E_{\mathrm{y}}=50 \mathrm{kV} / \mathrm{m}$ and $\mathrm{d}=0.1 \mathrm{~m}, \mathrm{U}_{\mathrm{d}}$ will be $2.5 \mathrm{kV}$. This voltage does not cause any corona discharges from the rounded corners of the instrument case.

Capacitive currents to a person in the electric field

The oapacitive current to a person standing in an alternating electric field can be measured by connecting him to the ground potential via an $\mathrm{AC}$ ammeter. $\mathrm{He}$ must, however, wear insulating shoes during the measurement. The measured current will be on the order of $14 \mu \mathrm{A} / \mathrm{kV} / \mathrm{m}$ for a $50-\mathrm{Hz}$ field. It must be remembered, however, that other people standing near this person will disturb the electric field and thus the capacitive current.

Capacitive current measurements on a man of normal height can thus be used for rough but simple measurements of the mean field strength near the ground. A mean field strength value of about $70 \mathrm{~V} / \mathrm{m} / \mu \mathrm{A}(50 \mathrm{~Hz})$ can be used for the field strength calculation from the capacitive current when a man, $1.8 \mathrm{~m}$ tall, is standing upright in the field with his arms down. A dummy has been built for measurements of the internal distribution of the capacitive current to a man. The insulated dummy is painted with a semiconducting paint with a surface resistivity of about $1,000 \Omega$ per square. Its arms, legs, torso, and the two halves of its head are insulated from each other and connected to a central unit in the torso. At a junction in the central unit different connections of the body parts can be connected to one of three transient protected digital AC ammeters for the measurement of the currents between different parts of the body. The dummy can be connected to the ground via one hand or one foot. The "current distributions" in the body are thus measured for different ground contact points. The digital ammeters are visible through a shielding metal net at the front of the dummy (fig. 5).

The dummy can be set up in various natural work positions: upright or bent, with the arms down or with one or two arms up. Electrically connecting handtools can be attached to one hand. The

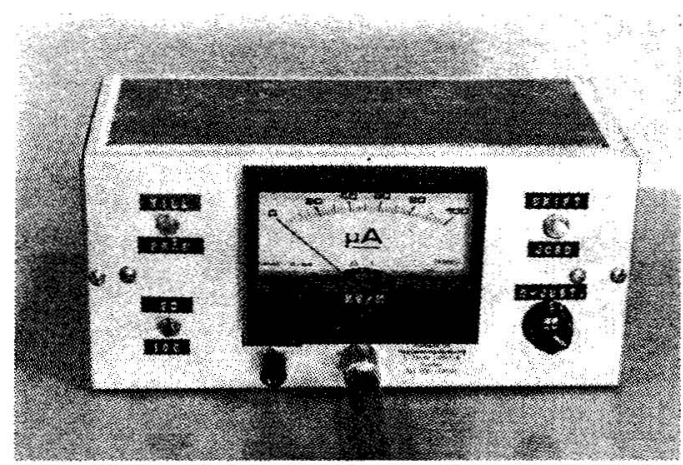

Fig. 4. Instrument for measurement of the AC electric field strength at points with nonzero potential - front panel.

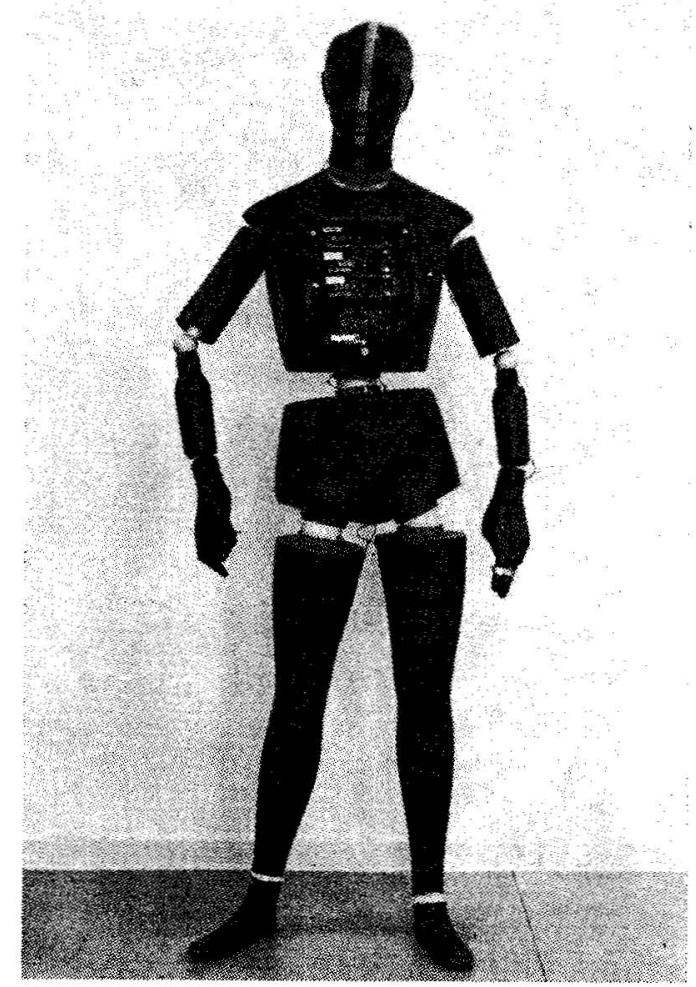

Fig. 5. Dummy for measurement of the distribution of capacitive currents to different parts of the body. 
Table 1. Electric field strengths, in a 400-kV substation, measured with the capacitive probe at the ground $\mathrm{E}_{0}$ and on top of the head of a man $\mathrm{E}_{1,800}$.

\begin{tabular}{lccr}
\hline Construction part & Distance $(\mathrm{m})$ & $\mathrm{E}_{0}(\mathrm{kV} / \mathrm{m})$ & $\mathrm{E}_{1,800}(\mathrm{kV} / \mathrm{m})$ \\
\hline Disconnector busbar (new) & 3 & 8.8 & 77 \\
Disconnector busbar (old) & 2 & 12 & 89 \\
Circuit breaker & 1 & 3.5 & 65 \\
& 4 & 9.4 & 73 \\
& 6.3 & 59 & 22 \\
\hline
\end{tabular}

shielding effect of different dry or wet clothes can be investigated with the dummy, as well as the effectiveness of the special shielding apparel constructed for EHV work.

\section{RESULTS}

The capacitive probe was used for several measurements in substations. Table 1 shows the electric fields measured at the ground near different construction parts in a substation. It also shows the electric field strength on top of the head of a person, $1.8 \mathrm{~m}$ tall, standing at the same positions.

The probe proved to be very simple to use, but, as the measurements were

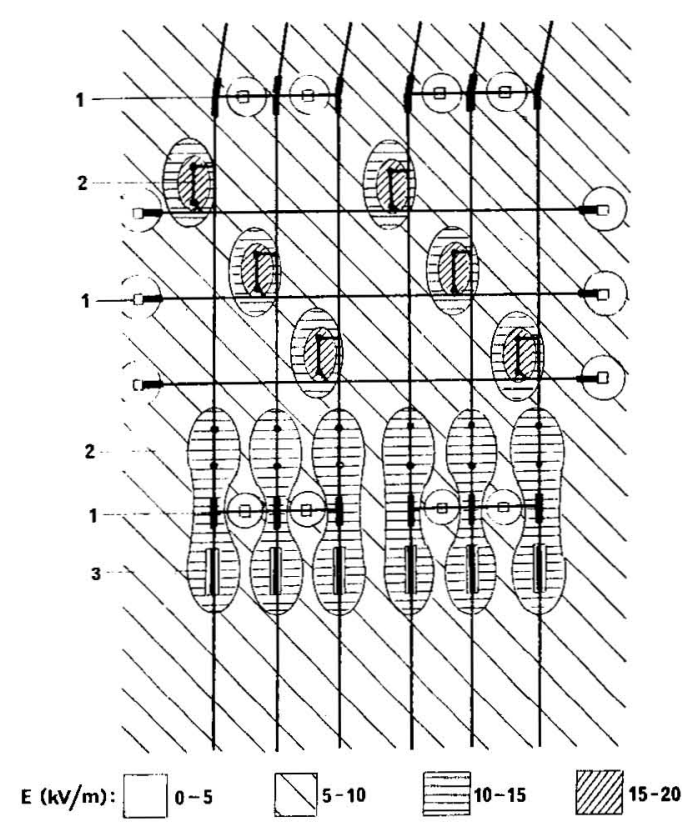

Fig. 6. Electric field strengths in a $400 \mathrm{kV}$ substation. $(1=$ steel tower, $2=$ disconnector busbar, and $3=$ circuit breaker) limited to grounded surfaces, it was impossible to use under certain conditions, e.g., when the ground was covered with high grass or snow. The electric field strength at the ground is furthermore very inhomogeneous due to the local topography of the ground. The probe is, however, convenient for measurements at constructions or on the surface of various objects like vehicles.

The dipole probe was only used for the mapping of the field strengths in one substation. It is very easy and rapid to use, held by the hand, and the accuracy of this method of operation is satisfactory. Fig. 6 shows a map of the field strengths measured at a height of $1.8 \mathrm{~m}$ in a 400 $\mathrm{kV}$ substation. The values measured at the Swedish $400 \mathrm{kV}$ substation have been compared to values reported from measurements in the U.S.S.R. $(7,8)$. The values obtained agree within $30 \%$. A preliminary measurement has been made of the field strengths in a $220 \mathrm{kV}$ substation. It shows that the field strengths at a height of $1.8 \mathrm{~m}$ are approximately half of those in the $400 \mathrm{kV}$ substation. The measurements made in the U.S.S.R. also show a rapid increase in the field strengths at a height of $1.8 \mathrm{~m}$ with the operating voltage (7).

\section{Capacitive current distribution}

The capacitive current distribution to a person in an electric field was measured with the dummy at two different places in a substation with different field strengths at the ground, $8.6 \mathrm{kV} / \mathrm{m}$ and $18 \mathrm{kV} / \mathrm{m}$, respectively. Table 2 shows the currents measured in different parts of the body for two attitudes of the body and for the dummy insulated or connect- 
ed to the ground via one hand or one foot. The total current to the ground was measured. The values are shown in table 3 , they are compared to those reported by other authors and to the theoretically calculated value for a person $1.75 \mathrm{~m}$ tall.

\section{DISCUSSION}

The measurements that will be made during the study of EHV substations will cover substations of different ages and types of construction. A special survey will be necessery for the groups doing maintenance work at circuit breakers. As the work is done partly on top of the breakers, this survey should cover the whole-breaker constructions at different heights.
A study of the time required for different types of work in the work areas in different field strength zones will follow the field strength measurements. The exposure to the field strengths can then be calculated.

Practical measurements of electrical discharges to persons during ordinary work are very inconvenient since the measuring equipment must be connected both to the persons studied and to the earth and this set-up involves certain hazards. Such measurements are planned, however.

The mean intensity of the discharges can be calculated. The number of discharges does certainly vary widely for different types of work and clothing.

It has been recommended in the U.S.S.R. that all discharges to personnel be elim-

Table 2. Capacitive currents to different parts of a dummy.

\begin{tabular}{|c|c|c|c|c|c|c|}
\hline \multirow{2}{*}{$\begin{array}{l}\text { Position } \\
\text { Arms down }\end{array}$} & \multirow{2}{*}{$\begin{array}{l}\begin{array}{l}\text { Ground } \\
\text { connection }\end{array} \\
\text { insulated }\end{array}$} & \multicolumn{3}{|c|}{$\begin{array}{l}\text { Current } \\
\text { measured }\end{array}$} & \multirow{2}{*}{$\begin{array}{c}\mathrm{E}=8.6 \mathrm{kV} / \mathrm{m} \\
\mathrm{I}(\mu \mathrm{A}) \\
20\end{array}$} & \multirow{2}{*}{$\begin{array}{c}\mathrm{E}=18 \mathrm{kV} / \mathrm{m} \\
\mathrm{I}(\mu \mathrm{A})\end{array}$} \\
\hline & & head & to & torso & & \\
\hline & & arms & $»$ & $»$ & 14 & - \\
\hline & & legs & $»$ & $»$ & 58 & 132 \\
\hline \multirow[t]{3}{*}{ One arm up } & insulated & head & $»$ & $n$ & 20 & 45 \\
\hline & & arms & $»$ & 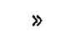 & 30 & 49 \\
\hline & & legs & $»$ & $»$ & 74 & 158 \\
\hline \multirow[t]{3}{*}{ Arms down } & to one arm & head & $»$ & $»$ & 26 & 51 \\
\hline & & arms & $»$ & $\gg$ & 61 & 165 \\
\hline & & legs & $»$ & $»$ & 11 & 13 \\
\hline \multirow[t]{3}{*}{ One arm up } & to one arm & head & $\gg$ & $»$ & 24 & 48 \\
\hline & & arms & $\gg$ & $\gg$ & 66 & 140 \\
\hline & & legs & $»$ & $»$ & 11 & 13 \\
\hline \multirow[t]{3}{*}{ Arms down } & to one leg & head & $»$ & $»$ & 26 & 51 \\
\hline & & arms & $»$ & $\gg$ & 23 & 47 \\
\hline & & legs & $»$ & $》$ & 85 & 186 \\
\hline \multirow[t]{3}{*}{ One arm up } & to one leg & head & $»$ & $»$ & 24 & 50 \\
\hline & & arms & $》$ & $»$ & 41 & 103 \\
\hline & & legs & 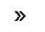 & $»$ & 89 & 233 \\
\hline
\end{tabular}

Table 3. Capacitive current to a man exposed to a $50-\mathrm{Hz}$ homogeneous field strength of $1 \mathrm{kV} / \mathrm{m}$.

\begin{tabular}{lll}
\hline Measurement & Author & I $(\mu \mathrm{A})$ \\
\hline $\begin{array}{l}\text { Measured for a group of men } \\
\text { mean height }=1,750 \mathrm{~mm}\end{array}$ & Schneider et al. (15) & 14 \\
$\begin{array}{l}\text { Measured for a cylinder } \\
\text { height }=1,750 \mathrm{~mm} \text { diameter }=250 \mathrm{~mm}\end{array}$ & Schneider et al. (15) & 14 \\
Measured with the dummy & $\begin{array}{l}\text { Lövstrand } \\
\text { (present investigation) }\end{array}$ & 12 \\
$\begin{array}{l}\text { Measured in a substation } \\
\text { Falculated for a semispheroid } \\
\text { height }=1,750 \mathrm{~mm} \text { diameter }=400 \mathrm{~mm}\end{array}$ & $\begin{array}{l}\text { Lövstrand } \\
\text { (present investigation) }\end{array}$ & 10 \\
\hline
\end{tabular}


inated. This seems to be an unrealistic requirement.

A.t present the exposure to field strengths is recommended for use as the single parameter of stress related to the EHV. The constructed instruments make measurements of this exposure possible. A correlation analysis can thus be made of exposure to field strengths of the personnel and the observed health deviations, if any, by the medical investigation.

If any negative health effects are found in the investigation, it might be necessary to limit occupational exposure to electric fields. It is possible to decrease the field strengths with various types of shields or shielding clothes. The use of such are discussed in reports from the U.S.S.R. (8). The dipole instrument can then be useful as a control instrument for occupational safety since it is reliable and simple to use.

\section{ACKNOWLEDGMENTS}

The author wishes to express his sincere thanks to Prof. Stig Lundquist for his great interest in the investigation, Mr. Bengt Nordström for his valuable assistance during the measurements, the electrical and mechanical workshops at the Research Institute of Electricity for their assistance in constructing the instruments, and the Swedish State Power Board together with the Swedish Work Environment Fund for their financial support of the work.

\section{REFERENCES}

1. ALLAN, R. N. and SALMAN, S. K. Electrostatic fields underneath power lines operated at very high voltages. Proc. inst. electr. eng. 121 (1974) 1404-1408.

2. ASANOVA, T. P. and RAKOV, A. I. The state of health of persons working in electric field of outdoor 400 and $500 \mathrm{kV}$. switchyards. Hyg. labour prof. dis. 5 (1966).

3. BARNES, H. C., MC ELROY, A. J. and CHARKOW, J. H. Rational analysis of electric fields in live line working. IEEE trans. power appar. syst. PAS-86 (1967): 4, $482-492$.

4. DENO, D. W. Calculating electrostatic effects of overhead transmission lines. Institute of Electrical \& Electronics Engineers, Power Engineers Society's winter meeting, New York, N.Y. January 27 February 1, 1974.

5. DENO, D. W. Electrostatic effect induc- tion formulae. IEEE trans. power appar. syst. PAS-94 (1975) 1524-1536.

6. FERN, W. J. and BRABETS, R. I. Field investigation of ozone adjacent to high voltage transmission lines. Institute of Electrical \& Electronics Engineers, Power Engineers Society's winter meeting, New York, N.Y. January 27 - February 1, 1974.

7. FILIPPOV, V. I. The effect of A-C electric field on man and measures of protection. Presented at the International Social Security Association meeting, Köln 1972.

8. FILIPPOV, V. I. and MOROZOV, Y. A. The protection from influence of electromagnetic fields and electrical current in industry. Trans. vsesojoznij tsentralnij naucho issledovatelskij institut ochrani truda (Moscow) 1973, pp. 7-43.

9. GRANDJEAN, E. Die biologische Wirkungen ionisierter Luft und ihre Bedeutung für die Klimatisation. Schweiz. Bl. Heiz. Lüft. 30 (1963): 4, 1-8.

10. KOROBKOVA, V. P., MOROZOV, Y. A., STOLAROV, M. D. and YAKUB, Y. A. Influence of the electric field in 500 and $750 \mathrm{kV}$ switchyards on maintenance staff and means for its protection. Conference international des grand réseaux électricite a haute tension (CIGRE) session August 28 - September 6, 1972

11. KREUGER, A. B. Air ions and physiological function. J. gen. physiol. (1962): 45, 233 41 .

12. LLAURADO, J. G. and BATTOCLETTI, J. H. Biologic and clinical effects of lowfrequency magnetic and electric fields. Charles C. Thomas Publ., Springfield, Ill. 1974, pp. $53-61$.

13. MEDA, E., CARRESCIA, V. and. CAPPA, S. Experimental results from exposure of animals to a.c. electric field Bulletin (International section of the ISSA for the prevention of occupational risks due to electricity) 3 (1974) $19-31$.

14. MILLER, C. J. The measurement of electric fields in live line working. IEEE trans. power appar. syst. PAS-86 (1967) $493-498$.

15. SCHNEIDER, K.-H., STUDINGER, H. WECK, K.-H., STEINBIGLER, H., UTMISCHI, D. and WIESINGER, J. Displacement currents to the human body caused by the dielectric field under overhead lines. Conference international des grand réseaux électricite a haute tension (CIGRE) session, August 21-29, 1974

16. SHAH, K. R., TORRI, J.F. and HANCOCK, J. T. More than appearance to EHV line design. Energy international July (1975) $22-24$.

17. SINGEWALD, M. L., LANGWORTHY, O. R. and KOUWENHOVEN, W. B. Medical follow-up study of high voltage linemen in a.c. electric fields. Institute of Electrical \& Electronics Engineers, Power Engineers Society's winter meeting, New York, N.Y. January 28-Febrary 2, 1973. 